\title{
El papel como artefacto y comunicación en Guaman Poma: palabra e imagen en la Nueva corónica ${ }^{1}$
}

\author{
Guaman Poma's Paper Trail: Word and Image in the New Chronicle \\ Regina Harrison \\ Universidad de Maryland, College Park, Maryland, Estados Unidos \\ Contacto: reglee@umd.edu \\ https://orcid.org/0000-0002-8066-1727
}

\begin{abstract}
Resumen
En tanto traductor, testigo y litigante, Felipe Guaman Poma encarna la implementación de las instituciones administrativas y jurídicas del Perú colonial. En textos letrados, así como en los dibujos en blanco y negro de su obra, el autor andino hizo continuas referencias a los artefactos de papel de los procesos jurídicos españoles en su proyecto para preservar propiedades, así como prácticas culturales andinas. Este ensayo examina el conocimiento que Guaman Poma tenía de los formatos y procesos legales de su época y su programa para constituir un legado de justicia en los Andes. Mi estudio de textos ejemplares como la orden de amparo, la cédula y la permuta demuestra que el cronista indígena adaptó la ley española para que sirva a propósitos andinos. Partiendo de investigaciones realizadas por Adorno, Quispe-Agnoli, De la Puente Luna y Burns, este ensayo examina los conceptos europeos de ley y de historia considerados ventajosos por las comunidades indígenas de los Andes.
\end{abstract}

Palabras claves: Felipe Guaman Poma de Ayala; Orden de amparo; Cédula; Petición; Permuta; Historia andina

\begin{abstract}
As a translator, a witness, and a litigant, Guaman Poma well serves to describe the implementation of Spanish administrative and juridical institutions in colonial Peru. In lettered texts, as well as in black and white drawings found in his Nueva Corónica, Guaman Poma references the paper artifacts of Spanish juridical processes in his project to preserve native Andean cultural practices and properties. This essay examines his knowledge of legal processes, legal formats, and his program for a legacy of justice in the Andes. In closely studying exemplary texts such as the writ of amparo, cédula (decree) and permuta (exchange), Guaman Poma uses Spanish law for his Andean purposes. With attention to previous research by Adorno, Quispe-Agnoli, de la Puente Luna, and Burns, this study examines concepts of European law and history deemed advantageous for native Andeans.
\end{abstract}

Keywords: Felipe Guaman Poma de Ayala; Writ of amparo; Paper trail; Decree; Petition; Andean history

Recibido: 12.07.19 Aceptado: 15.10.19 
Paper is a tenacious substance, which can be cut or torn, $[\ldots]$ being neither brittle like glass, nor woven like cloth, but having fibers, and not distinct threads, just as natural substances, so that scarcely anything similar can be found amongst artificial substances, and it is absolutely singular ${ }^{2}$.

(Sir Francis Bacon, Novum Organum Scientarium, 1620, citado en Basbanes, 2013, p. 3)

La estima que Sir Francis Bacon tenía del papel se hace evidente en la cita anterior. Dicha consideración también se hizo patente en sus elogios a otras tecnologías como la pólvora, la brújula magnética y la imprenta. La admiración por el papel, una sustancia singular, se remonta por lo menos al año 105 d. C., cuando Cai Lun escribió las pautas para su manufactura en la corte del emperador Ho Ti en China. Sin embargo, la fabricación del papel es aún más antigua que la fecha de este episodio y posiblemente se puede fechar en el año 140 a. C., como se aprecia en fragmentos provenientes de una tumba china en la provincia de Shaanxi. Amediados del siglo VIII d. C., los árabes dominaban el arte de fabricar papel y su uso se extendió por el Medio Oriente, el norte de África y España. Aunque el papiro tuvo gran protagonismo como vehículo transmisor de la escritura en la Antigüedad, los pensadores posteriores hicieron hincapié en la eminencia del papel. Los miembros del califato islámico abasí, por ejemplo, daban gran importancia a las hojas de papel para administrar su imperio regido por documentos gubernamentales. El papel se volvió imprescindible en la esfera musulmana desde tiempos antiguos y se utilizó en el proceso creativo y artístico. Una vez liberada de la necesidad de recurrir solo a la memoria oral, la sabiduría de las civilizaciones árabe, griega, asiáticas e hindú se podía registrar y conservar en un medio tangible como el papel. Asimismo, tal como muchos investigadores han apuntado en sus estudios sobre los orígenes del papel, desde China al Medio Oriente, la Península Ibérica y el norte de Italia, la ruta de la seda tuvo un rol fundamental en el movimiento de este rastro documental (Basbanes, 2013, pp. 7-11, 48-59). 
España se benefició de la tecnología árabe para la elaboración de papel y Córdoba fue la sede de producción de papel en Iberia. Jaime I de Aragón utilizó papel árabe en lugar de papiro o pergamino para su correspondencia administrativa de 1238. El papel aportaba una superficie idónea para la escritura, resistía las falsificaciones, era portátil y facilitaba a los escritores un medio ágil para componer textos. Siglos más tarde, Felipe II utilizaba tanto el papel que lo apodaron "el rey del papel". El rey prefería las peticiones escritas antes que las audiencias orales (Müller, 2014, p. 33). Por ejemplo, en marzo de 1571, el monarca revisaba 40 peticiones cada día. En 1580, mandó a hacer un sello con su firma para aligerar la firma de documentos. Por supuesto, sus numerosos cuestionarios, solicitudes de mapas y cuadros de datos exigían copiosas resmas de papel. El papel se convirtió entonces en aliado del rey a quien le gustaba blandir manojos de este durante el transcurso de sus audiencias. Müller relaciona el poder del papel en el gobierno de esta manera:

[...] en el mundo de Felipe II, el papel, en su función doble de portador de secretos y barrera de acceso al soberano, ayudó a cambiar el centro del poder a la esfera de la invisibilidad y esto influyó en la modernización de la administración del Estado moderno temprano. (2014, p. 34)

En esta época, la calidad del papel y su apenas perceptible marca de agua "equivalía[n] a la vestimenta" cortesana y eran indicadores de un estatus especial o de su ausencia. Las dimensiones de las misivas, color, ortografía, espacios en blanco, márgenes y marcas de agua heráldicas hacían sobresalir el estamento jerárquico del remitente y del destinatario (Müller, 2014, p. 75). En tal sentido, las marcas de agua "AA", "IA" y "GM" que se encuentran en las páginas de los manojos 1, 5, y 22 del manuscrito de Guaman Poma revelan las fuentes europeas de origen de papel de alta calidad (Boserup y Adorno, 2003, pp. 138-140). Aunque no sabemos precisamente cómo el cronista andino obtuvo papel como este, es posible pensar que lo haya adquirido cuando fue intérprete y asistente de Cristóbal de Albornoz en las campañas de extirpación de idolatrías, a través de sus colaboraciones artísticas con fray Martín de Murúa, o como traductor y garante de los títulos de propiedad de tierras en Huamanga. La cruz 
latina con forma aovada y las letras "GM" en el manuscrito de Copenhague son "muy similares a la mayoría del papel utilizado en la copia del Getty Murúa" (Turner, 2014, p. 108).

El papel fue un artículo de consumo de notable valor para Guaman Poma y su época. Rolena Adorno ha analizado el afán del autor por llenar cada página de su obra con una letra mesurada. Este es también el caso en aquellas en las que hace enmiendas y/o añadidos con oraciones apretadas en los espacios en blanco de la página. Adorno sugiere la posible escasez de papel cuando Guaman Poma estuvo en las últimas etapas de su proyecto. De ser así, el autor se vio obligado a abandonar su plan original de escritura, de hojas dobles y reforzadas, y comenzó a usar hojas sueltas que se pegarían (Adorno, 2003, p. 49). De hecho, el mismo autor nos dice que tiene mucho que decir $-\mathrm{y}$ escribir-, pero no tiene suficiente papel para hacerlo. Ello se aprecia en su relación de las características negativas del líder borracho don Juan Capcha que no cuenta en totalidad porque no hay suficiente papel para resumir todas sus faltas: "no fuera bastante una rresma de papel" (p. 793)³.

Guaman Poma apreciaba los sistemas incas de comunicación como el quipu y el tocapu. Por eso, su texto está lleno de dibujos en tinta que acompañan su prosa e indican la manera en que los reinos andinos se administraban por medio del quipu y las convenciones geométricas y abstractas de los tocapu. Los tocapu que aparecen en textiles, cerámica y arquitectura, transmitían información sobre jerarquías sociales y políticas. No obstante, numerosos ejemplos del texto guamanpomiano demuestran su tendencia hacia la escritura alfabética, sobre todo en las páginas dedicadas a correspondencia epistolar y documentos legales que seguían fórmulas retóricas específicas. Esta tendencia se manifiesta también en muchos dibujos de libros abiertos o cerrados. Su habilidad para leer y escribir lo llevó a un lugar prominente en su época como autor, notario, escribano y litigante, como veremos enseguida.

Rolena Adorno, Tom Cummins, Mercedes López-Baralt, Augusta E. Holland y Rocío Quispe-Agnoli han llamado la atención sobre la fascinación del cronista con la obra de los escribas, y han enfatizado su comprensión del poder del decreto real y de la interacción de imagen y escritura que enriquece 
sus ilustraciones. Observamos también su atracción, casi fetichista, hacia pedazos sueltos y tangibles de papel mientras escribía su obra. En la Nueva corónica, Guaman Poma incluyó copias de cartas, llenando páginas enteras del manuscrito, y dibujó trozos de correspondencia oficial con una letra sumamente legible en hojas pequeñas que aparecían en las manos de funcionarios trazados en los bocetos. El cronista también introdujo copias de documentos históricos para enfatizar la capacidad de los letrados de construir archivos históricos por medio de la escritura. Además, incluyó páginas de breviarios y cuadernos de contabilidad, dejando evidencia de su admiración por el poder de la palabra escrita. Este ensayo parte justamente de la admiración y respeto que Guaman Poma tenía ante la escritura y el papel, que iban de la mano con su conocimiento de procesos legales, formatos jurídicos y del programa de justicia que aspiraba a implementar en los Andes. Para acercarme a esta experiencia del escritor andino, ya he estudiado en trabajos anteriores dos ejemplos textuales de la Nueva corónica: una orden de amparo y un ejemplo de testamento. Ambos constituyen evidencias de modelos textuales jurídicos para el uso de peticionarios y litigantes indígenas, que buscaban asegurar que la reglamentación española cumpliera con sus intereses (Harrison, 2014 y 2015). En las páginas que siguen estudio mecanismos adicionales de escritura (cédulas, cartas de justicia, permutas y peticiones) que estaban al alcance de las poblaciones indígenas y que formaban parte del plan que Guaman Poma adjudicaba al papel y a la escritura alfabética: garantizar la restitución y la justicia.

\section{Esbozando los rastros de papel}

Por lo menos al principio de su trabajo, Guaman Poma tuvo a su disposición cantidades de papel, un hecho que ha dado lugar a comentarios y estudios sobre la relación entre los códigos de escritura alfabética y sus respectivos dibujos figurativos. En su examen del manuscrito, Adorno advierte que la imagen dibujada inevitablemente antecede al texto escrito: "Cada uno de los 398 dibujos de Guaman Poma, en el anverso o reverso de la hoja, deparan una presentación que luego es ampliada por la escritura en una página de prosa, o más" (2003, p. 54). Cummins concuerda con esta observación, ya que la imagen y la palabra no 
son entidades diferenciadas en la obra de Guaman Poma, sino más bien fluyen como una sola unidad. Las palabras son "imprescindibles" en los dibujos que se usan para establecer identidades de personajes, escribir títulos capitulares o efectuar un "acto discursivo" (Cummins, 1992, pp. 49-50).

Varios historiadores del arte han propuesto sistemas clasificatorios para esclarecer los vínculos que unen palabra e imagen. Las categorías usadas en estos sistemas clasificatorios sirven para deconstruir los juegos semánticos e interrelaciones inscritas visualizados en la obra de Guaman Poma. El análisis semiótico de Mieczyslaw Wallis (1973) provee el modelo genérico para estudios posteriores sobre el uso de la inscripción en el arte. Este analista describe las construcciones de palabra e imagen en el arte medieval como "enclaves semánticos" compuestos a partir de una variedad de signos convencionales destinados a suscitar asociaciones con sentimientos religiosos. Wallis organiza dichas construcciones en cuatro categorías: i) rótulos que transmiten información, ii) inscripciones que señalan discurso y/o diálogo, iii) invocaciones y iv) expresión estética sin vínculo aparente con la imagen como la firma del pintor. Estas inscripciones surgen en respuesta a patrones culturales y cronologías. Por ejemplo, Wallis apunta la disminución de inscripciones discursivas (diálogos) en las obras artísticas de la época renacentista. Esta disminución tuvo lugar a pesar de que el número de adagios inscritos en las pinturas aumentó; incluso aparecieron como elementos inseparables del mismo cuadro como, por ejemplo, una hoja escrita de papel que colgaba de un muro o una dedicatoria inscrita en una lápida. Además, en el siglo XVI las firmas de los artistas se destacaban visualmente en el cuadro. Estas usualmente usaban letras romanas, aunque otras veces era la firma individual de un pintor particular como El Greco o Rembrandt (Wallis, 1973, pp. 1-19).

John Sparrow (1969) continuó el estudio de inscripciones y diferenció entre inscripciones aleatorias y esenciales. Las aleatorias son las inscripciones impuestas a la obra sin que sean inherentes a la misma. En contraste, elementos esenciales que expresaban realismo eran considerados internos a la imagen. Ambas formas de inscripción podían aportar información fundamental descriptiva (rótulos) o podían proyectar un significado (mensaje) multidimensional y 
complejo. Por su parte, en su estudio de 1986, Dario Covi analizó las palabras escritas en cuadros renacentistas como títulos, epígrafes, explicaciones, nombres de figuras específicas e inscripciones que representaban el discurso. Anotó que estas expresiones se dirigían a lo representado en la pintura o servían para apelar a la atención del espectador. Covi distinguió entre las inscripciones que "flotaban" en la imagen del cuadro (como nombres propios y diálogo) y aquellas que formaban parte "integral" de la pintura. Esta última conformaba un efecto realista; por ejemplo, un libro con el título expuesto y situado en un anaquel dibujado dentro de la pintura es verídico ${ }^{4}$. Mientras ningún sistema puede abarcar todas las relaciones posibles entre palabra e imagen, muchos de los componentes del análisis de estos especialistas facilitan la comprensión del "enclave semántico" en los dibujos de la Nueva corónica como el siguiente:

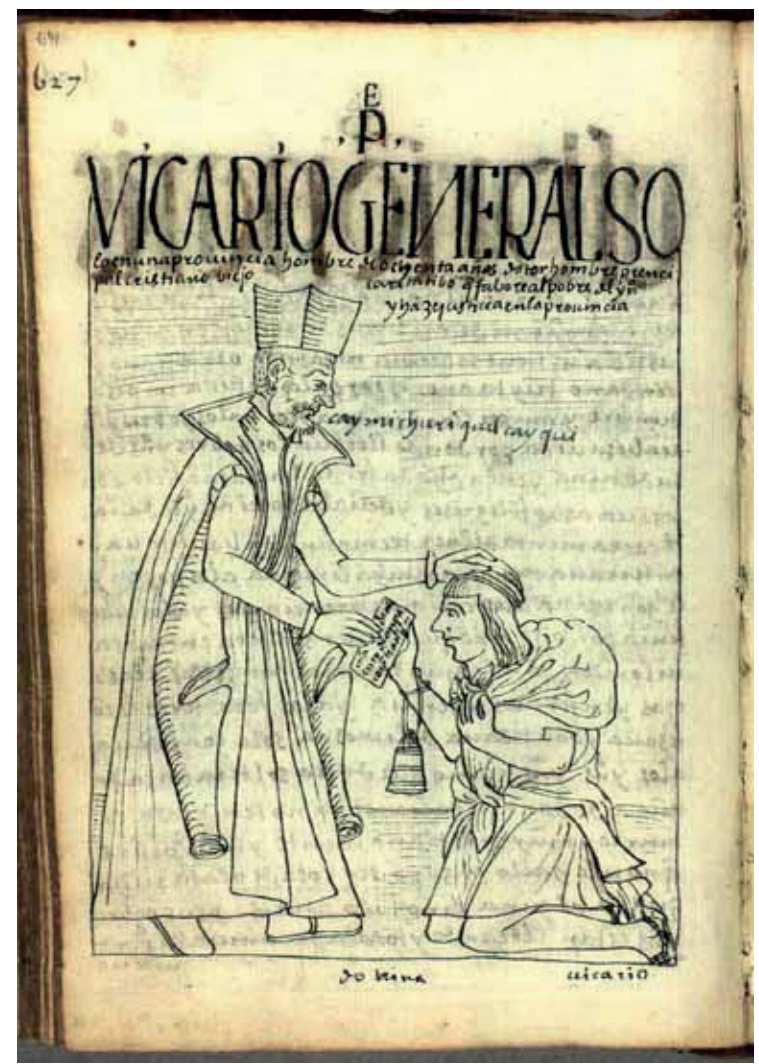

Figura 1. Nueva corónica y

buen gobierno (1615), p. 641. Biblioteca Real de Copenhague, Dinamarca. 
En el dibujo de la página 641 de la Nueva corónica, se hace evidente la confluencia de distintos niveles de significado visual y escrito según los cuales varios códigos de comunicación se activan. Este dibujo forma parte de un capítulo sobre el clero y muestra a un vicario español tocando la cabeza de un indio del pueblo que se arrodilla ante él. El humilde indio lleva un fardo grande a sus espaldas y viste sencillamente con una camisa-túnica de tela basta y sandalias. El vicario lleva prendas que lo revelan como miembro del clero: una capa elaborada y un tocado distintivo. De esta manera, se establecen visualmente las jerarquías del poder a través de los códigos de la vestimenta y el lenguaje corporal. Además, Guaman Poma refuerza la información dibujada con el texto escrito. En la parte superior de la ilustración se nombra al vicario y se alaban sus acciones caritativas que protegen a los indios de la provincia.

Dos actos comunicativos que ocurren en esta página nos llevan a un diálogo en varios niveles, simultáneamente. Las palabras del vicario, que flotan al lado de su boca, se emiten en quechua: "Caymi churi quilcayqui" (aquí, mi hijo, [está] tu papel). Este pronunciamiento en quechua que se dirige al indio arrodillado nos muestra al vicario de una manera positiva, ya que es un miembro del clero que puede conversar en quechua con sus feligreses analfabetos. Se destaca aquí el empleo de la palabra quilca, un lexema quechua utilizado en esta instancia para designar "papel". Quilca tiene una acepción rica y ambigua ya que hace referencia a un sistema semiótico de pintura, bordado y escultura y, más tarde, se usa para significar transcripciones alfabéticas y el papel (Grube y Arellano, 2002, pp. 56-57; Cummins, 2002, pp. 211-212; Quispe-Agnoli, 2006, p. 185). Asimismo el vicario se dirige al lector de la Nueva corónica que quizás no comprenda la frase en quechua. Su mano derecha extiende el papel ceremoniosamente hacia el lector desde un ángulo que permite el desciframiento del mensaje, así como de su composición. El mensaje es "integral" al tema del dibujo, pues estamos ante un pedazo de papel con una inscripción que se hace visible: "mandamiento de amparo. Confiad". De esta manera, mientras se proclama la bondad del vicario hacia el indígena a través del gesto paternalista, las palabras del título, la frase en quechua y las inscripciones legales en el papel 
respaldan y extienden la información transmitida por los distintos códigos, tanto lingüísticos como pictóricos.

El amparo, el mensaje escrito aquí, facilitaba la intervención administrativa en asuntos indígenas ya que se trata de "una orden para exigir de los oficiales indicados que protegieran al peticionario en lo relativo a la tenencia de la tierra o en el ejercicio de una función que el demandante temiera le fuese injustamente cuestionada o prohibida" (Borah, 1983, p. 53). Estas órdenes han sido revisadas minuciosamente - como lo ha hecho Brian Owensby en el caso de la Nueva España - con el objetivo de resumir las circunstancias particulares de individuos y comunidades que solicitaban dicho amparo de los funcionarios españoles y, a veces, en contra de ellos (2008, p. 52). Los elementos de un amparo son provistos por Guaman Poma, cuya obra brinda las fórmulas jurídicas correctas a sus lectores y asegura, por ende, el éxito de la demanda. El texto de Guaman Poma ofrece una petición de amparo ejemplar que, si bien está abreviada aquí, incluye lenguaje legal estándar: "por su Magestad le defiendo y anparo a Domingo Alcas, yndio rreseruado, o yndia biuda Maria Timtama deste dicho pueblo. Y que no pague tributo ni acuda a las demás seruicios personales" (p. 516). En general, los derechos a tierras y edificios también gozaban del poder escrito del amparo.

Guaman Poma estaba muy consciente de los medios para inscribirse a sí mismo y a su comunidad en los marcos jurídicos españoles. En sus páginas, despliega una oleada de actividades legales: una gran cantidad de peticiones, pleitos y otros documentos que eran utilizados por los notarios indígenas de los Andes $^{5}$. Nuestro autor hace hincapié en la creación y la conservación de estos documentos escritos en su debido formato, tal como se ve en el comentario que destina al rey:

Que todas las justicias seglares y gl[e]ciásticos destos rreynos rreciuan las peticiones y memoriales, enterrogatorios, abisado o carta que los yndios lo dieren y presentaren, aunque sea en lengua de yndio. Aunque sea un rreglón, al pie de ella lo rrresponda y con la rrespuesta se las buelva para su derecho, justicia, aunque sea yndio alcalde. Jamás haga justicia de palabra, cino que sea de letra, para que le conste al dicho corregidor. Si uiniere de palabra, no le oyga y pida escrito. (p. 831) 
Es posible que la obsesión guamanpomiana con la escritura y sus herramientas haya surgido de una decisión legal de 1530 que introdujo el cognitio summaria para simplificar los pleitos civiles de los pueblos indígenas. Mediante la determinación oral de los casos por un juez español, sin documentos y sin reglamentación de proceso, se resolvía rápidamente el litigio. Su intención era agilizar los procesos jurídicos de alto costo y sustituirlos por audiencias informales. Sin embargo, en el caso de pleitos entre indígenas y españoles, o disputas que involucraban pueblos enteros, el proceso exigía a menudo la comparecencia de una nómina de testigos (30 testigos era una práctica común), además de la documentación probatoria que, a su vez, daba lugar a 30 preguntas pertinentes al caso (Borah, 1982, pp. 14, 35, 56). Además, la insistencia española sobre el derecho de apelación significaba que los indios "podrían arrastrar a cualquier funcionario a la corte para desafiar sus decisiones" (Borah, 1982, p. 40). De hecho, muchos indígenas se acogían al mismo derecho como una oportunidad para reivindicarse. Las investigaciones de Woodrow Borah, como he señalado antes, han constituido un gran avance en este tema y han servido de base para otros estudios. John Charles señala que el Segundo Concilio Limense (1567) alentaba a los magistrados eclesiásticos a que escucharan argumentos orales en un pleito, en lugar de peticiones escritas, con el objetivo de facilitar resoluciones más rápidas (2010, p. 39). A su vez, Alan Durston (2008) ha rastreado los intentos del virrey Toledo para contener litigios, en vista de la documentación voluminosa en la época colonial. Un dictamen de 1574 limitaba, además, el acercamiento de los indios al corregimiento y a las cortes de Audiencia; nombraba “jueces naturales" para resolver demandas de manera oral y no por escrito. Este decreto también redujo el número de abogados conocidos como "protectores de naturales". Al año siguiente, Toledo determinó que los alcaldes indígenas administrarían justicia por medio de audiencias orales (Durston, 2008, p. 66). Pero a pesar de estas resoluciones legales, Guaman Poma aconsejaba conservar las resoluciones de las audiencias por escrito, para luego reportar las decisiones al corregidor. 
El interés de Guaman Poma por la palabra escrita y la referencia a las leyes españolas se hacen evidentes en el código de inscripciones que, con frecuencia, eran integrales y realistas, como la muestra del papel en el dibujo (figura 1) o como las inscripciones impuestas en los dibujos, los diálogos (speech scrolls). El análisis de estos dibujos y textos permite rastrear la divulgación del material escrito y nos ayuda a identificar estrategias jurídicas y discursivas de litigantes indígenas, aunque la investigación de José Carlos de la Puente Luna (2015) demuestra que no solo los nobles indígenas aprovecharon el sistema jurídico español. De todos los amparos dibujados por Guaman Poma, la mayoría atañe a la jurisdicción eclesiástica; así, respalda la observación de Durston de que las cortes eclesiásticas eran más receptivas a las comunidades indígenas (2008, p. 67).

Previamente había citado el dibujo del vicario que defendía a un indígena por medio de un amparo. En otro ejemplo pictográfico-textual seguimos otro litigio paso a paso: en él, un líder del cabildo indígena entrega una carta a otro personaje (figura 2). En este caso, el oficial indígena le da la misiva a una mujer solicitante que lleva a su hijo en sus espaldas y se arrodilla frente a él. Por medio de dicha carta escrita por este alcalde y miembro del cabildo, la persecución sacerdotal hacia esta mujer terminará pronto. La carta, que se muestra inclinada para que el lector pueda leer el texto, lleva una inscripción dirigida al cacique de su comunidad: "a mi señor cacique”. El título de esta página es didáctico porque indica las etapas posibles del recurso legal: nos informa que el cacique enviará esta queja al vicario quien, a su vez, la reenviará al obispo y finalmente se hará justicia contra el sacerdote abusivo. 


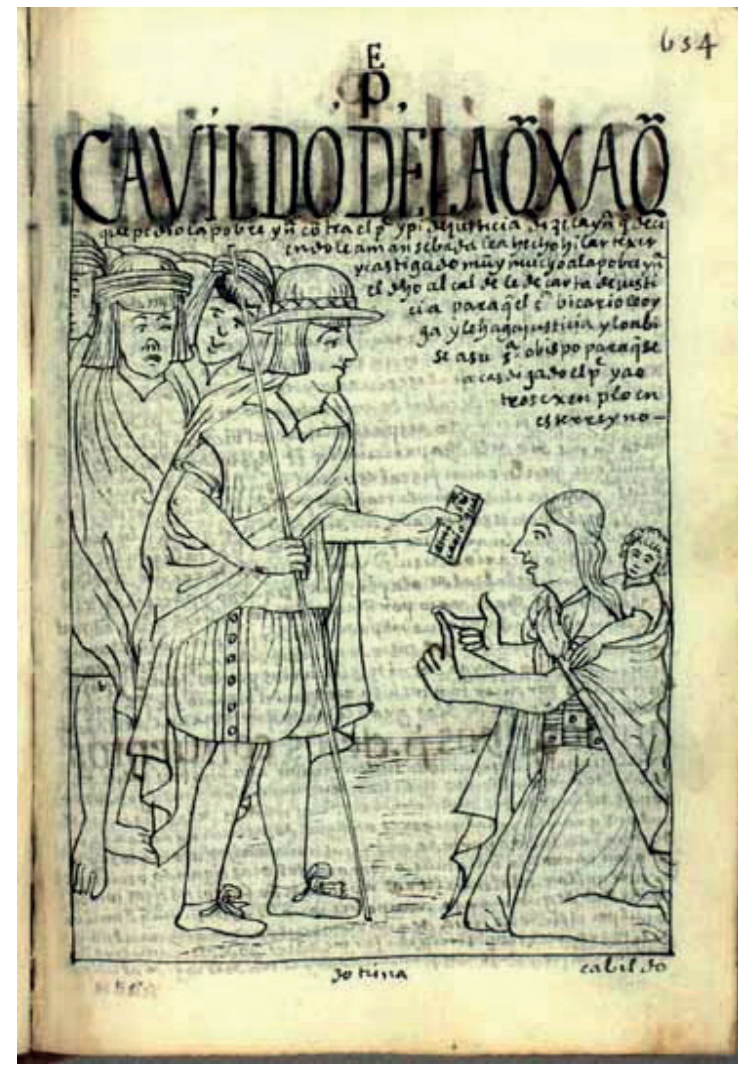

Figura 2. Nueva corónica y buen gobierno (1615), p. 668.

Biblioteca Real de Copenhague, Dinamarca.

Una descripción más compleja de las cortes eclesiásticas se encuentra en el dibujo de unas permutas, un título legal que es una resignación o renuncia que dos eclesiásticos hacen de sus beneficios en manos del ordinario, con súplica recíproca para que dé libremente el beneficio del otro. En esta ilustración se destacan las permutas en las manos (véase figura 3). 


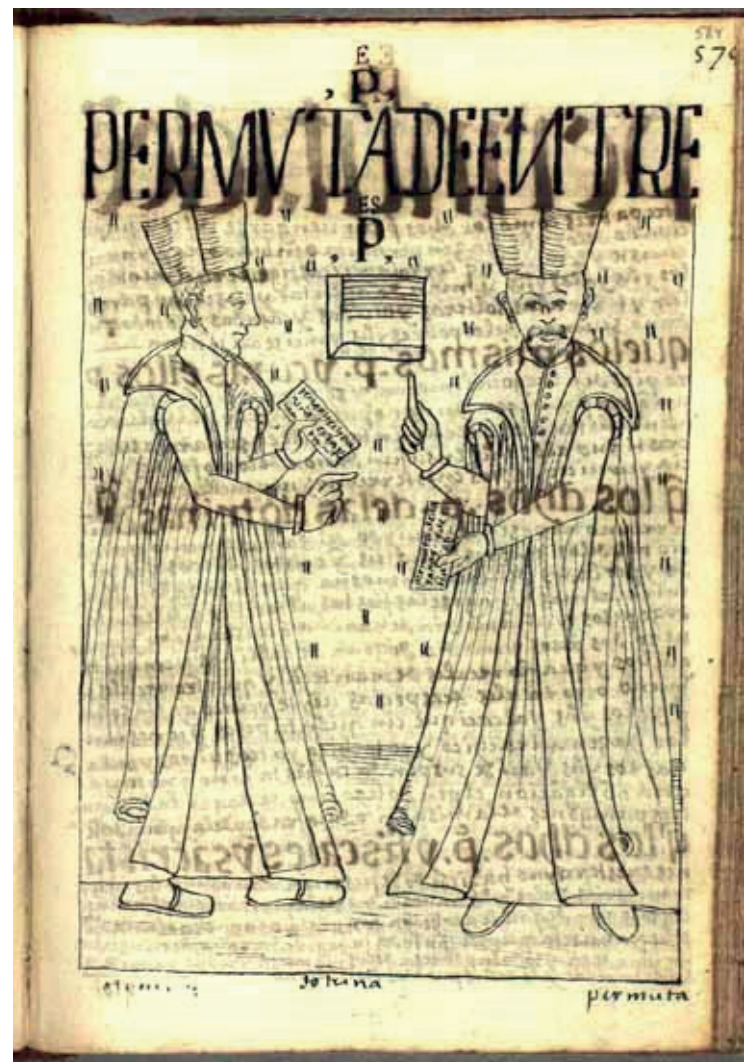

Figura 3. Nueva corónica y buen gobierno (1615), p. 584.

Biblioteca Real de Copenhague, Dinamarca.

Un sacerdote le entrega al otro un pedazo de papel en el que consta "Tengo hecho a vuestra Merced esta $\mathrm{p}$ [er] muta", mientras que en el otro el papel es visible "Permuta de Uayanay y de Santiago". Las inscripciones se pueden leer fácilmente dado que los dedos de los curas no ocultan la escritura en los papeles. Además, los dedos índices de ambos llaman la atención del lector al poder de la letra legal. Un dedo índice horizontal apunta al intercambio de documentos, mientras que el dedo índice del otro sacerdote señala el cielo y la legislación divina. Guaman Poma embellece su prédica visual con una explicación en prosa. Él resume los detalles de la permuta: con un cambio de funcionarios en la doctrina 
parroquial, llegará un nuevo cura con órdenes de castigar al cacique principal y a la comunidad entera (p. 585).

En otro dibujo que ilustra la importancia del papel, un sacerdote está sentado ante su escritorio con sus utensilios de escritura, mientras escribe una petición que señala: "Don Juan Pilcone de Apcara, curaca camachicoc: Digo que el corregidor me pide yndio para traxeneador" (p. 602). El mensaje en el papel es completamente visible, posicionado bien encima de la mesa, dictado por el cacique que se encuentra al lado del cura. Parece entonces que este sacerdote actúa a favor del cacique que se queja del corregidor español, ya que este le ha exigido de manera ilícita que un cargador indio porte sus pertenencias a todos lados. Sin embargo, el texto en la página siguiente provee información adicional que contradice la benevolencia de esta imagen:

Como haze peticiones los dichos padres y curas de las dichas dotrinas destos rreynos o los dichos bicarios por rrebolber a los dichos corregidores con los prencipales. Hazen las dichas peticiones con sus manos y nota y mandan que tengan pleyto y encisten quanto puede porque se rrebuelba la tierra. Después queda rrey[é]ndose del corregidor y de los prencipales; por detrás manda castigar al prencipal y anci vengan ellos. (p. 603)

Guaman Poma revela aquí que a menudo los curas instaban a los caciques a reclamar las acciones de corregidores $u$ otros funcionarios españoles o indígenas, para que cundiera el desasosiego dentro de la comunidad. Dicho esto, los sacerdotes no eran el único grupo equipado con pluma y tinta para defender los intereses de los indios. Por ejemplo, en la página 784 de la Nueva corónica leemos que un noble indígena inició un pleito teniendo cuidado de que textos escritos (recibos, declaraciones formales) respalden el litigio. El pago de un arancel para la Iglesia se representa en un recibo que el líder indígena escribe en la mesa, rodeado por sus instrumentos de escribir. Su texto dice lo siguiente "De terzio de San Juan pago 80 pesos Pedro N.". El título del dibujo amplía el propósito pedagógico-moral de Guaman Poma: el noble indígena conoce "la letra y lengua del español" y puede escribir una petición, elaborar un interrogatorio y encauzar un pleito. El interrogatorio es un recurso legal de importancia básica, como lo señala Jeremy Mumford: 
Según el procedimiento castellano civil, el demandante preparaba preguntas y citaba testigos para comparecer frente a un juez. Ocasionalmente los testigos contestaban de modo inesperado a las preguntas y añadían sus propias informaciones. De igual modo y con frecuencia, simplemente afirmaban, negaban o reclamaban ignorancia a cada pregunta del interrogatorio. (2008, p. 115)

En otra muestra de actividades con el papel como protagonista, Guaman Poma despliega una imagen de cómo el Estado satisface exigencias de mano de obra. Así, un capitán del ayllu sostiene en su mano una cédula de alquiler (permiso) que comprueba que él ha autorizado la sustitución del trabajo forzoso (mita) en la minería (p. 535). Una vez más, Guaman Poma insiste en anotar transacciones en forma permanente por medio del papel y aboga por el acto formal de registro. El papel aquí es una cédula que afirma que un indio pobre fue alquilado para trabajar en una mina y reemplazar a otro que se había enfermado por el envenenamiento de azogue. La cédula de papel señala que se ha recibido el pago del capitán por esta transacción. Eventualmente, Guaman Poma regresará a esta página y agregará un comentario moral y didáctico, ya que, al parecer, el dibujo solo no era suficiente. De manera desafiante, el cronista andino señaló que este pago, representado por el saco lleno de monedas y por una moneda en particular, debería transferirse al trabajador alquilado. Entonces, el mismo dinero del "alquiler" podría ser encauzado para pagar el tributo.

El tema del papel y la moneda aparecen también en la página 525 (figura 4) en la cual un escribano español escribe una petición frente a un indio de la comunidad: El indio está de pie a un lado de la mesa de escribir. Entre los útiles típicos de un escribano de cabildo, hay muchas monedas que quedan relegadas a la esquina de la mesa y otras aparte apiladas en el centro. El notario y el indígena tributario conversan bruscamente con frases flotantes alrededor de sus respectivas bocas: "Paga", ordena el notario y la respuesta en quechua del indio dice: "Caymi cino" (aquí tiene, señor). La carta contiene una inscripción legible y tiene como destinatario a: "don Diego de Mendoza, corregidor desta provin [cia]". Lo que sucede en esta escena se explica por su título: el indio empobrecido está sobornando al notario codicioso. Una explicación más detallada de los distintos tipos de soborno se ofrece en la página siguiente: 


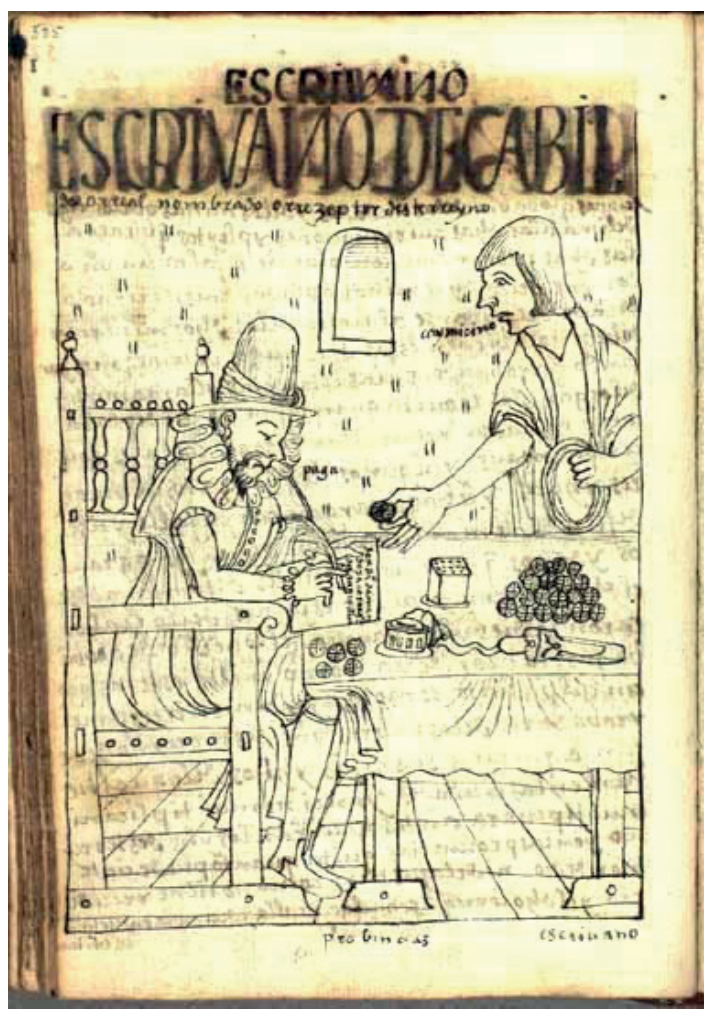

Figura 4. Nueva corónica y buen gobierno (1615), p. 525. Biblioteca Real de Copenhague, Dinamarca.

Que los susodichos escrivanos rreciben grandes cohechos de los caciques prencipales y de los pobres yndios con color de dalle mandamiento o de otros pleytos o dalle testimonio para la audiencia o para yr a cobrar los tributos a sus yndios de cada pueblo y de otras cosas, que gastan más en los testimonios que lo que an cobrado. (p. 526)

En su detallado análisis sobre textos mundanos escritos en quechua, Alan Durston (2008) sostiene que los casos civiles y eclesiásticos se presentaban mejor en castellano, lo que explicaría la relativa escasez de textos legales que poseemos en lenguas andinas, sobre todo si lo comparamos con los muchos que han sobrevivido del virreinato de Nueva España. Este es también el mensaje subyacente a estas inscripciones: todos estos documentos legales son escritos por curas y notarios en español y, solamente muy de vez en cuando, por dirigentes 
indígenas. Por esta misma razón, Guaman Poma insiste en que los caciques y funcionarios indígenas principales se sometan a exámenes de conocimiento del español escrito y de capacidad de hablar el idioma con soltura. De esta manera, las comunidades a las que sirvan estarán bien defendidas tanto en las cortes eclesiásticas como en las civiles. Aún más deseable sería el dominio del latín para "leer, escrevir, contar y sepa ordenar peticiones y enterrogatorios para defensa de sus personas y de sus yndios" (p. 785).

\section{Rastreando la documentación de papel: cartas de letrados}

La eficacia del papel en los marcos jurídicos coloniales se comprueba en los dibujos, inscripciones y comentarios prosísticos de la obra de Guaman Poma. Nuestro autor admira las virtudes de la palabra escrita en la correspondencia, en las palabras escritas entre funcionarios españoles y en las palabras registradas en papel entre españoles e indios. Guaman Poma valorizaba el acto de escribir y tenía consciencia de las pautas del estilo literario de su época, de la cortesía epistolar de saludos y despedidas formales y de cómo estructurar el hilo conductor narrativo para esclarecer mejor el significado del texto ante los ojos de su lector. Desde la perspectiva del cronista andino, la tecnología de la escritura no era algo mágico sino una tarea regida por convenciones formales. Él criticaba el estilo tosco de una carta hecha por el kuraka don Juan Capcha y, en contraste, alababa la elegante composición epistolar del cura Peralta (p. 793). La primacía de la escritura como vehículo de comunicación se manifiesta claramente también en el intercambio de cartas entre el cura y el dirigente indígena que Guaman Poma transcribe fielmente en su crónica, con los saludos, despedidas y la firma con su rúbrica.

La Nueva corónica incluyó también correspondencia primaria entre el rey Carlos V y Gonzalo Pizarro en la sección "Conquista” (pp. 418-420). Sus textos epistolares fueron adornados con las firmas prominentes de ambos personajes y con ornamentación gráfica de la mano de Guaman Poma, para lograr un efecto visual en el lector (figura 5). Es de notar que, a pesar de que el papel era un objeto caro y difícil de adquirir, las firmas mencionadas ocupan una parte considerable del espacio que la página dispone para escribir: 


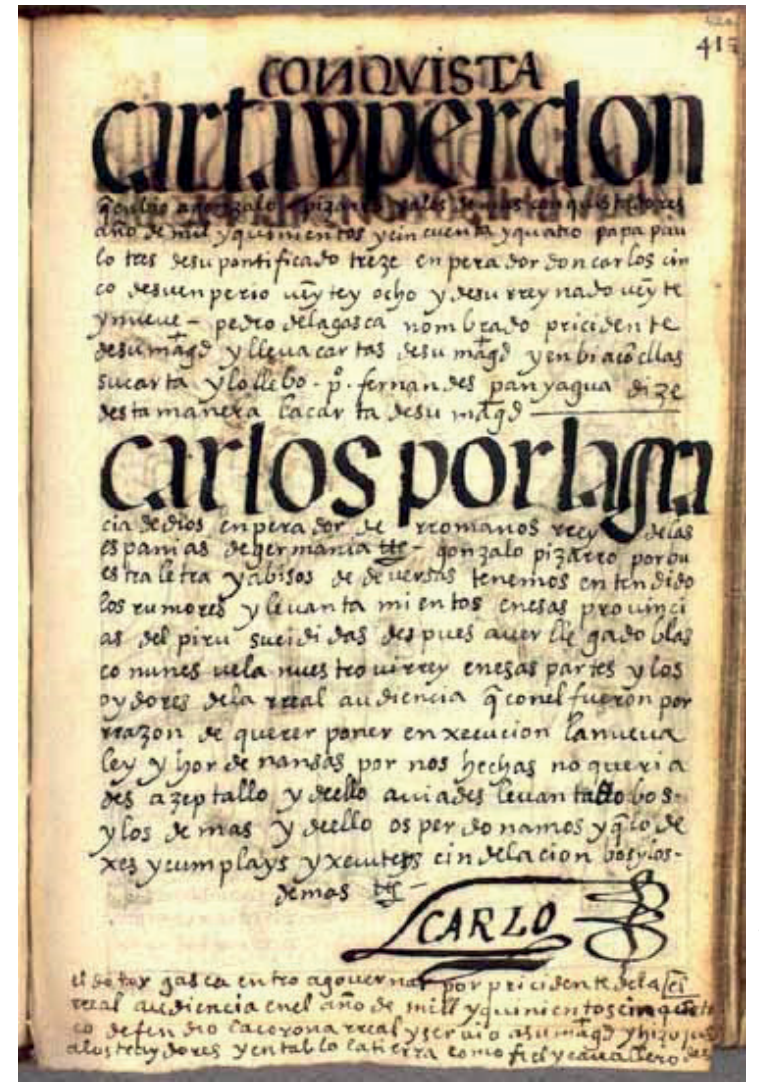

Figura 5. Nueva corónica y buen gobierno (1615), p. 420. Biblioteca Real de Copenhague, Dinamarca.

En ambas cartas, el texto es pulido y el tono cortés. La epístola de Pizarro se dirige dos veces al rey con la expresión requerida, "beso los rreales pies y manos su umilde bazallo" (p. 418). La supuesta carta del rey difiere en tono; es más escueta y parca, más oficial (p. 420). No hay ningún texto que coincida exactamente con esta carta de Gonzalo Pizarro incluida por Guaman Poma. Sin embargo, algunas fuentes de cartas originales, como las que ha reunido Juan Pérez de Tudela Bueso (1946), abarcan temas semejantes sobre la sublevación, la violencia y la necesidad de remediar la situación en los Andes, como también aparecen en el texto de Pizarro intercalado por Guaman Poma en las páginas de su Nueva corónica. 
Adorno ha indicado que Guaman Poma tuvo acceso a la Historia del descubrimiento y conquista del Perú (1555) de Agustín de Zarate y que refleja y condensa una carta de correspondencia (1986, p. 148, n. 6). Son transcritas fielmente en su Nueva corónica, palabra tras palabra, las primeras líneas de la carta del rey Carlos V a Pizarro, de la Historia de Zárate. Son temas históricos; el monarca menciona que él había recibido cartas de Pizarro, entre otros documentos relativos a los acontecimientos que se suscitaron una vez que el virrey que había designado llegara al Perú para implementar las Nuevas Leyes. En la carta que Guaman Poma copia de Zárate, originalmente fechada en 1544, se lee:

Gonzalo Pizarro: Por buestra letra y abisos de deuersas tenemos entendido los rrumores y leuantamientos en esas prouincias del Piru sucididas después auer llegado Blasco Nuñes Uela, nuestro uirrey, en esas partes y los oydores de la rreal audiencia que con él fueron por rrazon de querer poner en xecución la nueua ley y hordenansas por nos hechas. (p. 420)

Sin embargo, Guaman Poma omite frases de la carta original transcrita por Zárate como "para el buen gouierno dessas partes y buen tratamiento de los naturales" que está incluida en la carta original hecha por el rey, fechada de 1554 (Zárate, 1955 [1555], p. 307). Esta omisión va de la mano con la inserción de un texto que no estaba en la misiva de Carlos V. En esta, Guaman Poma escribe atrevidamente un perdón real para Gonzalo Pizarro y los otros rebeldes: "Y de ello os perdonamos" (p. 420). Guaman Poma termina la transcripción de la carta real con una firma del monarca de tamaño considerable, prueba de la bondad de este monarca en los días iniciales de la sublevación.

El dibujo de la página 419 (figura 6) muestra al rey con una carta en la mano, y esta ilustración enfatiza visualmente el tema del perdón que supuestamente concedió a Pizarro. 


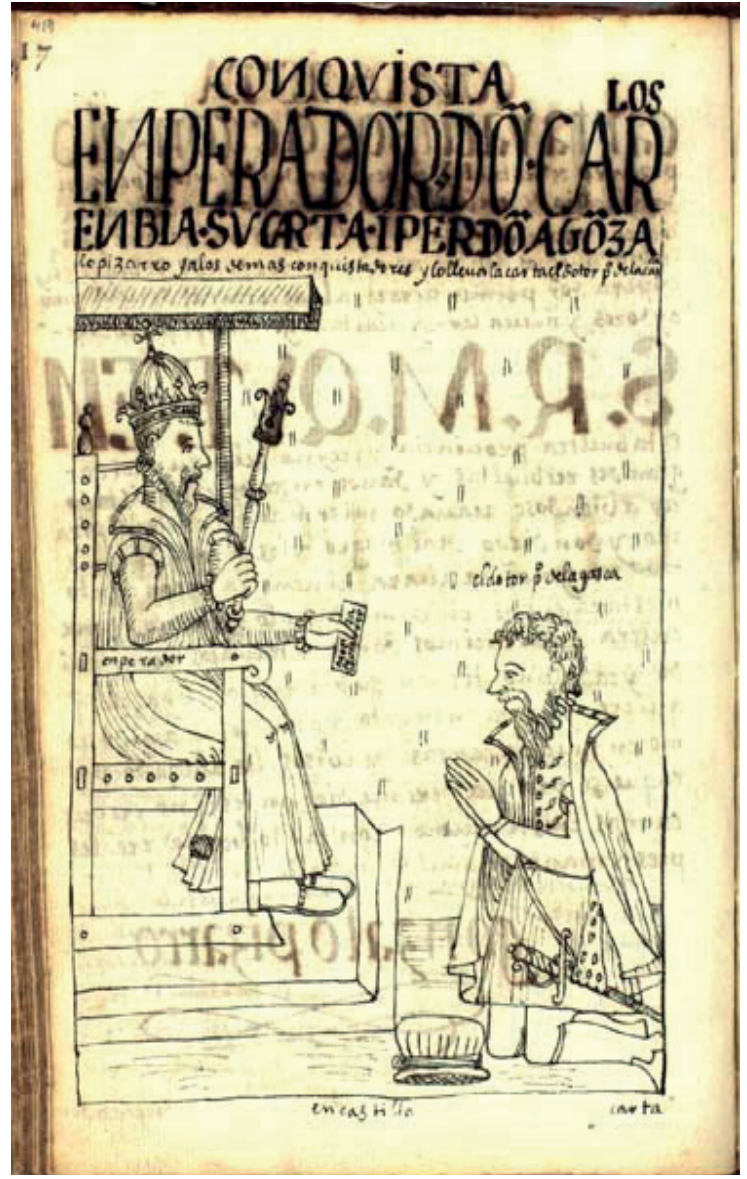

Figura 6: Nueva corónica y buen gobierno (1615), p. 419. Biblioteca Real de Copenhague, Dinamarca.

Los personajes destacados en esta ilustración son el rey Carlos V, sentado en su trono, y Pedro de La Gasca, emisario humilde arrodillado a sus pies. Sin embargo, el elemento semiótico dominante aquí es la carta que el rey extiende a La Gasca. Se ve claramente en su inscripción que el destinatario de este papel es Gonzalo Pizarro. Su nombre se destaca en el cuadro del documento y se ha escrito con tanto esmero que ni el pulgar del monarca puede ocultarlo. El título de este dibujo elimina cualquier duda respecto a su contenido: "Enperador Don Carlos enbía su carta i perdón a Gonzalo Pizarro y a los demás conquistadores" (figura 6). Por lo visto, esta epístola tenía tanta importancia que Guaman Poma provee una ilustración del acto mismo de entrega 
del perdón de la mano del rey a la de La Gasca, quien la recibe. La carta de perdón entonces forma parte integral del texto, aunque seguramente Guaman Poma reconoce las acciones tiranas y traidoras del rebelde.

En su estudio de 1986, Adorno advirtió que el cronista andino tuvo acceso, además de Zárate, a la obra de autores como Bartolomé de Las Casas, fray Luis de Granada y Luis Jerónimo Oré, entre otros. Él cita a estos autores y compara sus propios actos literarios con los de ellos. Un ejemplo notable se encuentra en la "carta" de presentación de su obra ante el rey, según la cual explica las deficiencias de su crónica:

[es] escrito y debojado de mi mano y engenio para que la uaridad de ellas y de las pinturas y la enbinción y dibuxo a que vuestra Majestad es enclinado haga fázil aquel peso y molestia de una letura falta de enbinción y de aquel ornamento y polido ystilo que en los grandes engeniosos se hallan. (p. 10)

Su apología retórica responde a las fórmulas de humildad definidas por Ernst Curtius y constituye un ejemplo de afectada modestia, cuyo objetivo era neutralizar la asumida soberbia del autor y captar la buena disposición del lector.

Ahora bien, esta declaración de humildad puede ser más complicada. Investigaciones recientes acerca del manuscrito Historia del origen y genealogía real de los reyes ingas del Pirú (designado el Códice Galvin-Murúa) han revelado una carta en principio escondida tras una ilustración. Cummins estudió este texto del cronista Martín de Murúa, que data de 1590, y anotó que el parecido entre esta carta y la de Guaman Poma es innegable:

Libro, dibujado de mi mano Para que la variedad, de los colores Y la ynbencion dela pintura, a que, V Mag.d es ynclinado Haga facil aquel pesso y molestia de una letura falta de ymbençion $\mathrm{E}$ de auel ornamento y pulido Estilo que En los grandes Yngenios solo se Hallan. (Murúa citado por Cummins, 2014, p. 62, n. 36)

Cummins concluye entonces que Guaman Poma operó préstamos textuales del manuscrito de Murúa. Juan Ossio, quien ha revisado en detalle el contenido de estos textos, comparte la conclusión de Cummins. Aun así se destacan divergencias entre ambos autores en lo que se refiere a su presentación 
de sí mismos y sus motivos ideológicos. Por ejemplo, Guaman Poma anota que él no ha tenido educación formal: "[mi] poco uer y poco sauer, y no ser letrado ni dotor ni lesenciado ni latino" (p. 8). En cambio, la declaración de humildad de Murúa se limita a lamentar sus debilidades de estilo y proclamar su capacidad investigadora. De hecho el cronista mercedario enfatiza sus dotes de investigación al citar los testimonios de cinco oficiales incas y otros testigos indígenas que le habían suministrado información ${ }^{6}$.

Murúa no duda en elogiar su labor en la búsqueda de la verdad histórica y señala los factores que la han obstaculizado, como la ausencia prehispánica de escritura alfabética: "se deuia a una yistoria E gouierno tam peregrino e con razón tan espantossa a todo el mundo, Por ser istoria sin Escriptura Ninguma, Mas de por los quipus y memoria del [sic] los yndios antiguos y viejos..." (Murúa citado por Cummins, 2014, p. 62). Por calificar la historia y gobierno incaicos de "tan espantossa a todo el mundo, Por ser historia sin Escriptura Ninguma", el cura deslegitima los grafismos andinos, señalando, dicho sea de paso, la "superioridad" europea. Ossio concuerda con Cummins en que Murúa "lamenta la falta de documentación escrita de las fuentes", pero evalúa como positivo su afán por servir a su rey y componer una historia en español derivada de múltiples fuentes indígenas (2014, p. 22).

Es evidente que Guaman Poma copió el modelo de la carta de Murúa para hablar de las dificultades al redactar su obra. A diferencia de Murúa, Guaman Poma manifestó su respeto por los sistemas andinos de registro de información y comunicación en la Nueva corónica. El autor enfatizó también la recolección de datos legítimos a partir de fuentes andinas: "no hallando supgeto en mi facultad para acauarla conforme a la que se deuia a unas historias sin escriptura nenguna, no más de por los quipos y memorias y rrelacciones de los yndios antigos..." (p. 8). Su deseo, expresado también en su prólogo a los lectores cristianos, era "sacar en limpio" - y sobre todo escritas en papel- estas historias que carecían de alfabeto ("ni letra alguna") y que se contaban en varios idiomas nativos ("todos los bocablos de yndios"). De esta manera, el cronista invitaba a su lector a sostener estos textos escritos, bajo la forma reconocible y sustancial de libro, en sus manos y leerlos en sus páginas: "que leyere deste dicho libro, biendo la ocasion en las manos al escrito" (p. 11). 
Otro pasaje de la Nueva corónica invita a la comparación con el texto de Murúa, ya que leemos en este que el fraile ha recogido su historia de varias fuentes indígenas (quipus, memorias y relaciones) y que, con mucho esfuerzo, ha podido convertir el producto de sus investigaciones en un texto de "frases y construcciones españolas" cuando declara: "Escoxí la lengua y fracis castellana" (Murúa citado por Cummins, 2014, p. 62). Ossio se pregunta aquí por qué Murúa escribió esta frase. Quizás el cronista mercedario estaba contemplando escribir en quechua o en latín. Tal vez Murúa albergaba dudas acerca del alcance de su prosa, o se cuestionaba si era capaz de capturar todos los detalles que deseaba expresar (Ossio, 2014, p. 22). Cualesquiera fueran los motivos del fraile, Guaman Poma supera aquí las intenciones del cronista mercedario, ya que no solamente declara que escribe con construcción sintáctica española elegante en su libro, sino que subraya también que ha utilizado catorce lenguas regionales en las cuales se ha plasmado la historia de los incas: "Escogí la lengua e fracis castellana, aymara, colla, puquina conde, yunga, quichiua ynga, uanca, chinchaysuyo, yauyo, andesuyo, condesuyo, collasuyo, cañari, cayanpi, quito" (p. 10). Recordemos entonces el tema de la necesidad de la destreza lingüística que repetía Garcilaso Inca cuando hacía su crítica de los autores españoles y su conocimiento imperfecto del quechua. Una vez más, en las páginas de la Nueva corónica, el importante tema vuelve a aparecer.

Guaman Poma estaba al tanto del poder de la palabra inscrita en el papel, lo cual fue una de sus motivaciones para componer su crónica. Por medio de la escritura y el dibujo impulsó su objetivo de imprimir un rastro de la memoria en una historia que perduraría, que se guardaría en los archivos de la burocracia española. En sus páginas finales leemos sobre este propósito en la voz del cronista andino: “[...] escribo esta historia para que sea memoria y que se ponga en el archibo para ver la justicia” (p. 991). Así, Guaman Poma daba fe de su anhelo por transformar el testimonio de los testigos, sabios y expertos del quipu e inscribir sus palabras en las hojas blancas de la historia. De manera similar al fraile mercedario, el autor andino había recogido la historia inca de múltiples fuentes nativas, y también se inspiró en parte en textos de Murúa. No obstante, cuando leemos su carta al rey en las primeras páginas de la Nueva corónica, nos 
damos cuenta de diferencias fundamentales en su elaboración de la historia y su programa para el uso de la historia:

[...] no hallando supgeto en mi facultad para acauarla conforme a la que se deuia a unas historias cin escriptura nenguna, no más de por los quipos y memorias y rrelaciones de los yndios antigos muy biejos $\mathbf{y}$ biejas sabios testigos de uista, para que de fe de ellos, y que ualga por ellos qualquier sentencia jusgada. (p. 8; el énfasis en negrita es mío)

La primera oración de esta cita sigue la perspectiva de Murúa: la falta de escritura incaica, el uso del quipu, la memoria de los indios antiguos. Ahora bien, la oración termina con una divergencia marcada. A diferencia del fraile, Guaman Poma valora la sabiduría de los ancianos, especialmente de las ancianas mujeres indígenas ya que ellas, por su experiencia como testigos de vista, también conocen la historia que narran.

Además de inscribir esta historia en el archivo del mundo, Guaman Poma comparte su motivación legal para escribir; elogia la confiabilidad de sus fuentes y anota su utilidad: "que de fe de ellos, y que ualga por ellos qualquier sentencia jusgada" (p. 4). Los lexemas relacionados con el registro y la ley que he mencionado antes son pertinentes. Sebastián de Covarrubias define "dar fe" como "testimonio auténtico, como la fe que da el escrivano" (1943 [1611], p. 587). Aquí Guaman Poma se enfoca en las implicaciones legales de su historia, que antes ha sido transmitida oralmente y que ahora se escribe. Además, Covarrubias define "sentenciar" como "definir en juyzio algún pleito" (1943 [1611], p. 933) que puede entenderse jurídicamente como "este testimonio es válido en cualquier caso legal que tenga necesidad de un veredicto". En tal sentido, Guaman Poma se aleja de Murúa y aboga por la autenticidad —y el estatus legal— de su libro, que transcribe testimonios verbales de individuos que carecían de escritura alfabética. Verbum e imagum fluyen entonces con igual facilidad de su tintero, dejando constancia de una historicidad incaica para la posteridad, que permite que la historia rectifique la injusticia. Para cumplir con su objetivo de lograr justicia en el mundo andino colonial, Guaman Poma emplea palabra e imagen en conjunto. Por medio de la prosa de sus órdenes jurídicas, por los retazos y las hojitas de papel dibujados en las manos de funcionarios eclesiásticos y administradores coloniales, así como en su uso de una correspondencia selecta de las cartas oficiales, logra presentar una 
comunicación histórica y jurisprudencial. Estas decisiones artísticas y textuales del cronista andino iluminan la existencia de una red compleja de interacciones basada en un artefacto valioso y permanente, la hoja de papel.

\section{Notas}

1 Primera traducción del inglés por S. Fredrick. Traducción final y revisada del inglés por R. Quispe-Agnoli. Todas las citas extraídas de textos en inglés han sido traducidas, por lo que las referencias a la paginación de las mismas corresponden a los textos en inglés citados en la bibliografía.

2 "El papel es una sustancia tenaz; se puede cortar o desgarrar, [...] no se rompe como el vidrio ni se teje como una tela pero tiene fibras, fibras que no se distinguen como las sustancias naturales, de modo tal que no se puede encontrar nada así entre las sustancias artificiales. El papel es absolutamente único.”

3 Todas las citas textuales provienen de la edición digital, con paginación corregida, que se puede consultar aquí: http://www.kb.dk/permalink/2006/poma/info/en/frontpage.htm (Guaman Poma, 2001 [1615]).

4 En Language in the Visual Arts (2014), Leslie Ross hace un resumen eficaz de los comentarios críticos y representaciones artísticas hasta la época contemporánea.

5 Sobre el tema de los escribanos indígenas coloniales, véase: Adorno, 1991 y 2012; Rappaport y Cummins, 2012; Burns, 2011; Charles, 2010.

6 Los nombres de dichos testigos se encuentran en Cummins, 2014, p. 59 n. 20.

\section{Referencias bibliográficas}

Adorno, R. (1986). Guaman Poma: Writing and Resistance in Colonial Peru. Austin: University of Texas Press.

Adorno, R. (1991). Images of Indios Ladinos in Early Colonial Peru. En K. J. Andrien y R. Adorno (Eds.), Transatlantic Encounters: Europeans and Andeans in the Sixteenth Century (pp. 232-270). Berkeley: University of California Press.

Adorno, R. (2003). A Witness unto Itself. En R. Adorno e I. Bosserup (Eds.), New Studies of the Autograph Manuscript of Felipe Guaman Poma de Ayala (pp. 7-106). Copenhague: Museum Tusculanum Press.

Adorno, R. (2012). Court and Chronicle: A Native Andean Engagement with Spanish Colonial Law. En S. Belmessous (Ed.), Native Claims: Indigenous Law Against Empire, 1500-1920 (pp. 63-84). Oxford: Oxford University Press. 
Adorno, R. y Boserup, I. (Eds.). (2003). New Studies of the Autograph Manuscript of Felipe Guaman Poma de Ayala's "Nueva corónica y buen gobierno". Copenhague: Museum Tusculanum Press.

Basbanes, N. A. (2013). On Paper: The Everything of Its Two-Thousand-Year History. Nueva York: Knopf.

Borah, W. (1983). Justice by Insurance: the General Indian Court of Colonial Mexico and the Legal Aides of the Half-Real. Berkeley: University of California Press.

Boserup, I. y Adorno, R. (2003). Watermarks in GkS 2232 4to and in the Two Martín de Murúa Manuscripts. En R. Adorno e I. Boserup (Eds.), New Studies of the Autograph Manuscript of Felipe Guaman Poma de Ayala's "Nueva corónica y buen gobierno" (pp. 133-140). Copenhague: Museum Tusculanum Press.

Burns, K. (2011). Making Indigenous Archives: The Quilcaycamayoc of Colonial Cuzco. Hispanic American Historical Review, 91(4), 665-689.

Carta del Rey a Gonzalo Pizarro. (1964 [1546]). En J. Pérez de Tudela Bueso (Ed.), Documentos relativos a don Pedro de la Gasca y a Gonzalo Pizarro (pp. 385-386). Madrid: Graficas Yagües.

Charles, J. (2010). Allies at Odds; The Andean Church and Its Indigenous Agents, 1583-1671. Albuquerque: University of New Mexico Press.

Covarrubias, S. de. (1943 [1611]). Tesoro de la lengua castellana o española, editado por Martín de Riquer. Barcelona: S. A. Horta.

Covi, D. (1986). The Inscription in Fifteenth Century Florentine Painting. Nueva York: Garland.

Cummins, T. B. F. (1992). The Uncomfortable Image: Pictures and Words in the Nueva Corónica i buen gobierno. En R. Adorno et ál. (Eds.), Guaman Poma de Ayala: The Colonial Art of an Andean Author (pp. 46-59). Nueva York: The Americas Society.

Cummins, T. B. F. (2002). Los Quilcakamayoq y los dibujos de Guaman Poma. En C. Arellano-Hoffmann, P. Schmidt y X. Noguez (Eds.), Libros y escritura de tradición indígena: ensayos sobre los códices prehispánicos y coloniales de México (pp. 188-215). Ciudad de México: El Colegio Mexiquense y Universidad Católica de Eichstadtt. 
Cummins, T. B. F. (2014). Debujado de Mi Mano: Martín de Murúa as Artist. En T. B. F. Cummins, E. A. Engel, B. Anderson y J. M. Ossio (Eds.), Manuscript Cultures of Colonial Mexico and Peru: New Questions and Approaches (pp. 35-65). Los Angeles: Getty Publications.

Durston, A. (2008). Literacy in Colonial Peru: The Question of Mundane Quechua Writing Revisited. Hispanic American Historical Review, 88(1), 41-70.

Grube, N. y Arellano Hoffman, C. (Eds.). (2002). Escritura y literalidad en Mesoamérica y la región andina: una colaboración. En C. ArellanoHoffmann, P. Schmidt y X. Noguez (Eds.), Libros y escritura de tradición indígena: ensayos sobre los códices prehispánicos y coloniales de México (pp. 27-63). Ciudad de México: El Colegio Mexiquense y Universidad Católica de Eichstadtt.

Guaman Poma de Ayala, F. (2001 [1615]). El sitio de Guaman Poma. Nueva corónica y buen gobierno. Copenhague: Biblioteca Real. Recuperado de http://www.kb.dk/permalink/2006/poma/info/en/frontpage.htm

Harrison, R. (2014). Sin and Confession in Colonial Peru: Spanish-Quechua Penitential Texts, 1560-1650. Austin: University of Texas Press.

Harrison, R. (2015). Guaman Poma: Law, Land, and Legacy. En R. Adorno e I. Boserup (Eds.), Unlocking the Doors to the World of Guaman Poma and His "Nueva corónica" (pp. 91-111). Copenhague: Museum Tuscalanum Press.

Holland, A. E. (2008). "Nueva corónica”: Tradiciones artísticas europeas en el virreynato del Perú. Cuzco: Centro de Estudios Regionales Andinos Bartolomé de Las Casas.

La Puente Luna, J. C. de. (2015). That Which Belongs to All: Khipus, Community, and Indigenous Legal Activism in the Early Colonial Andes. The Americas, 72(1), 19-54.

López-Baralt, M. (1988). Icono y conquista: Guaman Poma de Ayala. Madrid: Ediciones Hiperión.

Müller, L. (2014 [2012]). White Magic: The Age of Paper. Cambridge, Malden: Polity Press.

Mumford, J. R. (2008). Litigation as Ethnography in Sixteenth-Century Peru: Polo de Ondegardo and the Mitimaes. Hispanic American Historical Review, 88(1), 5-40. 
Ossio, J. M. (2014). New Assessment of the Hidden Texts in the Galvin Manuscript of Fray Martín de Murúa. En T. B. F. Cummins, E. A. Engel, B. Anderson y J. M. Ossio (Eds.), Manuscript Cultures of Colonial Mexico and Peru: New Questions and Approaches (pp. 11-35). Los Angeles: Getty Publications.

Owensby, B. P. (2008). Empire of Law and Indian Justice in Colonial Mexico. Palo Alto: Stanford University Press.

Perez de Tudela Bueso, J. (Ed.). (1946). Documentos relativos a don Pedro de la Gasca y a Gonzalo Pizarro. Madrid: Gráficas Yagües.

Quispe-Agnoli, R. (2006). La fe andina en la escritura: Resistencia e identidad en la obra de Guaman Poma de Ayala. Lima: Fondo Editorial de la Universidad Nacional Mayor de San Marcos.

Rappaport, J. y Cummins, T. (2012). Beyond the Lettered City: Indigenous Literacies in the Andes. Durham: Duke University Press

Ross, L. (2014). Language in the Visual Arts: The interplay of Text and Imagery. Jefferson: McFarland and Company.

Sparrow, J. (1969). Visible Words: A Study of Inscription in and as Books and Works of Art. Cambridge: Cambridge University Press.

Turner, N. K. (2014). Accounting for Unfinished History: How Evidence of Book Structure Provides a New Context for the Making of the Galvin and Getty Murúas. En T. B. F. Cummins, E. A. Engel, B. Anderson y J. M. Ossio (Eds.), Manuscript Cultures of Colonial Mexico and Peru: New Questions and Approaches (pp. 81-116). Los Angeles: Getty Publications.

Wallis, M. (1973). Inscriptions in Paintings. Semiotica: Journal of the International Association for Semiotic Studies, 9(1), 1-28. doi: 10.1515/ semi.1973.9.1.1

Zárate, A. (1955 [1555]). Historia del descubrimiento y conquista del Perú. Editado por Franklin Pease G. Y. Lima: Fondo Editorial de la Pontificia Universidad Católica del Perú. 